\title{
Enhanced support available for dental nurse apprenticeships
}

\section{Apprenticeship funding}

Any employer recruiting an apprentice

dental nurse between 1 August 2020 and 31

January 2021 may receive up to $£ 2,000$ to

help support costs.

On 8 July the government announced payments for employers who hire new apprentices related to a 'Plan for Jobs' created in response to the COVID-19 pandemic. $£ 2,000$ will be paid to employers in England for each new apprentice they hire aged under 25 , and a $£ 1,500$ payment for each new apprentice they hire aged 25 and over. These payments will be in addition to the existing $£ 1,000$ payment the government already provides for new 16-18-year-old apprentices, and those aged under 25 with an Education, Health and Care Plan - where that applies.

Any dental employer, for example a small independent dental practice, dental laboratory, large dental body corporate (it is not dependent on holding an NHS contract), NHS organisation or social enterprise in England, if recruiting a dental nurse or dental technician apprentice, may be eligible for the payment to help support employment costs.
Dental nursing is a popular apprenticeship with over 5,000 currently registered with the Education and Skills Funding Agency.

Dental organisations wishing to recruit a dental nurse or dental technician are best advised in the first instance, if not familiar with the apprenticeship process, to review the guidance and support available through https://www.gov.uk/government/collections/ apprenticeship-vacancies.

\section{Final exams}

In addition to the financial support available, the rules regarding undertaking the End Point Assessment (EPA) (the final set of examinations) for current dental nurse apprentices have been amended to reflect the changing situation in relation to the delivery of oral healthcare. Under normal rules a workplace observation forms part of the EPA process, however as this cannot currently be undertaken, a temporary discretion has been applied by the Institute of Apprenticeships and Technical Education (IfATE) in that: 'The workplace observation may be replaced by a factual record of observed practice from the on-programme assessment, validated by an expert witness. The apprentice will also have a Q\&A session with the external assessor to assess the practice and fill any gaps, ensuring that the relevant KSBs have been adequately covered.

For the full IfATE guidance (July 2020) visit https://www. instituteforapprenticeships.org/ apprenticeship-standards/dental-nurse/.

\section{Skills recovery}

In addition to supporting employment costs for apprenticeships, the government has announced exceptional funding as part of the wider COVID-19 skills recovery response. It is prioritising getting young people into work, an apprenticeship or other work-based training. Where these are not available, there is an offer of additional one-year courses in high value subjects to prevent students aged 18 and 19 from becoming NEET (not in employment, education or training).

For more information visit: https:// www.gov.uk/government/publications/ qualifications-in-covid-19-supportpackages.

\section{BDA Presidential}

\section{meeting}

A webinar will be held online on Wednesday 16 September at 20:00 to install new British Dental Association (BDA) President Russ Ladwa, who will give his presidential speech.

Outgoing President Roz McMullan will also deliver her valedictory address.

To register for the event, which is open to everyone, visit www.bda.org/ presidentialmeeting.

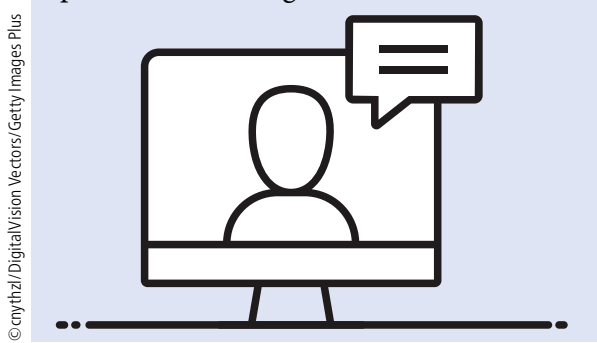

\section{BDIA launches new COVID-19'return to practice' products}

As part of the dental industry's ongoing support of the resumption of widespread dental treatment, the British Dental Industry Association (BDIA) has launched a new online directory of members' products and services that will allow dental practices to safely provide the best possible oral care to patients.

The new BDIA online initiative has grouped its members' products and services together into 13 key categories, covering the things that are most important to the resumption of activity and ongoing provision of treatment, such as PPE. It also includes a number of helpful links.

BDIA Chief Executive Edmund Proffitt said: 'With the concerns over counterfeit and non-compliant PPE and all today's challenges requiring practices to look at products and technologies to provide safe and effective care, it is more important than ever that purchases are made from suppliers that dental professionals can trust, such as BDIA members. I would urge all purchasers of dental equipment to have a look at our new website, and when they think supplier, think BDIA member'.

A user can simply choose a BDIA member from the list of suppliers of equipment and services and browse a full list of products available from that member. If they wish to purchase any products a direct URL will take the user to the supplier's website where they can purchase the item.

Visit www.bdia.org.uk/product-directory to find out more. 